\title{
Reseña. Marina Alvarado Cornejo, Revistas culturales y literarias chilenas de 1900 a 1920: legitimadoras del campo literario nacional. Santiago de Chile: Editorial Cuarto Propio, 2016.
}

Estamos ante un libro necesario e importante. Un libro que al hablarnos de un pasado que parece muy lejano, nos hace reflexionar también sobre temas y problemas absolutamente actuales que dicen relación con el desarrollo del campo cultural y comunicacional nacional, el que muestra como característica estructural central y predominante en los tiempos actuales, el proceso de segmentación de audiencias y heterogeneización cultural, que encuentra justamente antecedentes en la época y en los fenómenos a que alude el libro que comentamos.

El país del que nos habla el texto de Marina Alvarado es el que se puede denominar como el país liberal oligárquico, en tanto sociedad en la que se había plasmado una estructura política, económica, social y cultural que expresaba la plena instauración del capitalismo, como signo de la inclusión del país en la modernidad (Salazar). Estos complejos procesos se desarrollaron en una sociedad en la cual ni el tipo de economía y de crecimiento económico, ni el tipo de Estado y régimen político reconocían a la gran mayoría otro papel que no fuera el de 
CATEDRAL TOMADA: Revista de crítica literaria latinoamericana / Journal of Latin American Literary Criticism Reseña. Marina Alvarado Cornejo, Revistas culturales y literarias chilenas de 1900 a 1920: legitimadoras del campo literario nacional. Santiago de Chile: Editorial Cuarto Propio, 2016.

clases subalternas, brazos desde el punto de vista económico y masas sin participación activa, desde el punto de vista político.

De todas formas, el proceso modernizador había creado en nuestro país las condiciones políticas, económicas, sociales y culturales para la aparición de una auténtica prensa de empresa, que es la consumación de la libertad de prensa, en el marco del pensamiento liberal que hegemonizaba ideológica y culturalmente la sociedad chilena. Entre esas condiciones citadas se encontraban el crecimiento de las ciudades y de proporción de la población urbana; el desarrollo y crecimiento del aparato educacional y la reducción del analfabetismo, que había pasado de un $68 \%$ a fines del siglo XIX a un 50\% en 1920, como consigna el texto de Marina Alvarado; el desarrollo y expansión del campo cultural, al decir de Catalán (1985); los avances tecnológicos en la imprenta y un marco legal suficientemente permisivo como para hacer atractiva la inversión de capitales en el negocio periodístico, cuestión asegurada por la ley de imprenta liberal de 1872.

La modernización que se dio en el país en las primeras décadas del siglo veinte se manifestó también -sobre todo en las ciudades- en la vida cotidiana, en el uso del tiempo libre y en las costumbres, los tranvías eléctricos, las obras de alcantarillado, los teléfonos, el cine, el alumbrado público, la masificación de la zarzuela y del folletín, el primer vuelo en aeroplano, los automóviles y los primeros vehículos de transporte con motor a gasolina, que son algunas de las novedades del período. (Subercaseaux)

Lo antes dicho significa que se articularon tendencias más bien universales del desarrollo moderno con las características y formas específicas de la modernización capitalista chilena, emergiendo en nuestro país en sus características básicas un mercado informativo y cultural, que incluía un plano diferenciado de desarrollo de una esfera pública plebeya y popular, desde donde se articuló la lucha por la emergencia de una cultura popular masiva que reivindicaba la plena visibilidad y legitimidad de su carta de ciudadanía, lo que se expresó, entre otras expresiones, en la emergente actividad deportiva, en el teatro, en la lira popular y en el ámbito periodístico en la llamada prensa obrera. 
Esas fueron las condiciones que permitieron el desarrollo de un proceso de crecimiento explosivo del número de publicaciones periódicas que acontece en el cambio de siglo. Así, si en 1898 se contabilizaban 287 diarios, periódicos y revistas en el país, en 1902 éstos eran 406 y para 1914 ya alcanzaban a 531. (Correa et alia 75) Dicho proceso dio cuenta de la diversificación del campo periodístico y la aparición de nuevos formatos y géneros, así como se relacionó con la irrupción de nuevos medios como el cine y, en general, con una nueva percepción del tiempo y el espacio, de la ciudad, de la presencia cada vez más importantes de nuevos actores sociales y de la llamada cuestión social, etc.; por ello, es que podemos afirmar que para la prensa nacional, la primera década del siglo veinte muestra más bien un perfil claramente de transición entre un periodismo todavía tributario de los cánones decimonónicos en retirada y un tipo de prensa que caracterizó buena parte del desarrollo del campo en el siglo veinte y que se hizo crecientemente predominante.

En dicho contexto es que irrumpe la presencia de empresarios periodísticos y editoriales que protagonizan la modernización en estos ámbitos. La autora que reseñamos nos hace ver lo decisivo de la acción de Agustín Edwards, con la fundación de la edición santiaguina de El Mercurio (1900), seguida casi de inmediato de Las Ultimas Noticias de El Mercurio (1903), en lo que a diarios se refiere y la fundación de Zig Zag (1905), en el plano de las revistas, y a partir de la cual se desarrolló una industria editorial, fundamental para entender el fenómeno de la aparición y desarrollo de la revista especializada en contenidos, novedad total para la sociedad de la época.

Se ha remarcado que Edwards impulsó una lógica empresarial, donde la generación de utilidades, la inversión en nuevas tecnologías y la aplicación de estrategias eficientes de ventas y distribución jugaban un rol determinante. Para ello, organizó cuadros gerenciales que, además de sus conocimientos y aptitudes administrativas, tenían una visión muy completa del ejercicio periodístico; y 
CATEDRAL TOMADA: Revista de crítica literaria latinoamericana / Journal of Latin American Literary Criticism Reseña. Marina Alvarado Cornejo, Revistas culturales y literarias chilenas de 1900 a 1920: legitimadoras del campo literario nacional. Santiago de Chile: Editorial Cuarto Propio, 2016.

contrató periodistas profesionales, a tiempo completo. (Bernedo y Arriagada, 2002)

Por otro lado, otros empresarios, de Valparaíso, los Helfman, propietarios de la Imprenta Universo, habían fundado en 1902 la revista magazine Sucesos y pocos años después comprarían a Edwards la casa editorial fundada por aquel, cuando ya el despliegue de revistas especializadas dirigidas a públicos masivos (infantiles, magazines, femeninas, de espectáculos, de deportes, hípicas, etc.), se había consolidado en el mercado periodístico nacional. (García Huidobro y Escobar)

En esas condiciones, nos ilustra el libro de Marina Alvarado, se llevan a cabo los esfuerzos de las revistas literarias y culturales que analiza, las que “pertenecen a productores autónomos en la medida que estos se declaran distantes de las revistas publicadas por empresas culturales con fines comerciales", según las define Alvarado, y que, sigue diciendo, "el público objetivo de las producciones autónomas no es el "gran mercado", sino más bien un mercado "puro", constituido, en gran medida, por los mismos agentes que se declaran opositores a los intereses burgueses". Sin embargo, la misma autora nos advierte que el influjo y el crecimiento del mercado periodístico y cultural provocaron que muchos de los que trataban de impulsar estas revistas literarias y culturales, debieron trabajar en los otros medios pertenecientes a las empresas emergentes.

Entonces, el libro de Marina Alvarado nos presenta una realidad social y cultural que paulatinamente se complejiza y que, por tanto, ofrece diversas caras. Junto, y tal vez gracias al desarrollo del campo cultural es que se produce un nivel importante de autonomización del ámbito literario, aunque también puede ser quizás entendible como otra oferta y a sus revistas como una variante de las revistas especializadas. El fenómeno es complejo e interesante, porque contiene en sí el germen de la lógica de segmentación de audiencias y públicos y de heterogeneización cultural que, podemos afirmar, es la tendencia cultural, social y política predominante en la sociedad chilena actual. 
Por otro lado, el análisis que nos ofrece este libro sobre las revistas literarias y culturales nos permite, por así decirlo, completar el escenario o el mapa de la época en el ámbito periodístico, ya que vemos un sector del campo que asume un rol de elaboración de cierta particular discursividad, de la misma forma que está emergiendo otro actor que se expresa en la llamada prensa obrera (Arias). En igual medida, es destacable la relevancia que Marina Alvarado le confiere en estos procesos a la presencia de las mujeres, como escritoras o como público y en el marco de procesos más anchos y profundos que apuntan a la conquista de mayores espacios y derechos como actores protagonistas. Dichos fenómenos también estaban ocurriendo en otros sectores sociales, como ocurrió con la prensa obrera feminista de los periódicos La Alborada y La Palanca, que tuvieron a activistas como Carmela Jeria y Ester Díaz como dirigentes y periodistas. La primera de ellas también destacada por su capacidad oratoria, al decir de Recabarren, "novela guerrillera porteña que se eleva como chispa eléctrica entre las multitudes" (“El Proletario", 21 octubre 1905).

Gramsci señaló alguna vez que no somos sino huellas que la historia ha dejado en nosotros y que nuestro deber es hacer el inventario de esas huellas. El texto de Marina Alvarado contribuye a esa labor enriqueciendo el conocimiento de la época y sus condiciones, en que se echaron las bases de nuestro campo cultural y del posterior desarrollo a lo largo y ancho del siglo XX hasta la actualidad. Dichos procesos asumieron distintos perfiles, de acuerdo a los contextos históricos, pero en muchas ocasiones conservaron algunos rasgos que se delinearon en los orígenes que en este texto se rastrean y explican. Uno de ellos especialmente destacable es la concepción de la prensa no como puro reflejo o instrumento de dinámicas y lógicas exteriores a ella, sino como un actor sociocultural que opera desde sus propias instalaciones ideológicas y culturales, construyendo y difundiendo sentidos sobre lo social. No se trata, tampoco, de reclamar para la actividad de la prensa supuestas autonomías autárquicas. Por el contrario, se trata de poner el énfasis en las articulaciones y relaciones, siempre 
CATEDRAL TOMADA: Revista de crítica literaria latinoamericana / Journal of Latin American Literary Criticism Reseña. Marina Alvarado Cornejo, Revistas culturales y literarias chilenas de 1900 a 1920: legitimadoras del campo literario nacional. Santiago de Chile: Editorial Cuarto Propio, 2016.

complejas cuando no conflictivas, con otros espacios y con las discursividades que de ellos emanan.

Las revistas literarias y culturales de que nos habla Alvarado desarrollaron ese perfil y además, constituyen un antecedente de una tendencia vigente hasta la actualidad, cual es que todo grupo u organización social o cultural produce sus propios mecanismos e instrumentos expresivos, desde los que se articula con otros espacios sociales y comunicacionales y, al mismo tiempo, que dichos medios y su comúnmente difícil y esforzada supervivencia constituyen un elemento que dinamiza y fortalece a esos grupos. En definitiva, el presente libro nos ratifica nuevamente que si las cosas no siempre fueron como las conocemos (y padecemos) actualmente, no tienen por qué seguir siendo así en el futuro, lo que no es poco si de esperanzas se trata.

\section{Bibliografía}

Arias Escobedo, Osvaldo. La prensa obrera en Chile. Chillán: Ediciones U de Chile, 1970.

Bernedo, Patricio y Arriagada, Eduardo. “Los inicios de El Mercurio de Santiago en el epistolario de Agustín Edwards Mac Clure (1899-1905)”, HISTORIA N³5, Santiago de Chile: Instituto de Historia, P. Universidad Católica de Chile, 2002.

Correa Sofía, Figueroa, Consuelo, Jocelyn-Holt (et. alt). Historia del siglo XX chileno. Santiago de Chile: Editorial Sudamericana, 2001.

García Huidobro, Cecilia y Escobar, Paula. Una historia de las revistas chilenas. Santiago de Chile, Ediciones Universidad Diego Portales, 2012. 
CATEDRAL ToMAdA: Revista literaria latinoamericana / Journal of Latin American Literary Criticism Eduardo Santa Cruz

Gonzalo Catalán "Antecedentes sobre la transformación del campo literario en Chile entre 1890 y 1920”, en Brunner, José J. y Gonzalo Catalán, Cinco estudios sobre cultura y sociedad. Santiago de Chile: FLACSO, 1985.

Salazar, Gabriel. Historia de la acumulación capitalista en Chile. Santiago de Chile: LOM Ediciones, 2003.

Subercaseaux, Bernardo. Genealogía de la vanguardia en Chile. Santiago de Chile: Ediciones Facultad Filosofía y Humanidades, Universidad de Chile, $(\mathrm{s} / \mathrm{f})$. 